\title{
Review Article \\ History and Actual State of Non-HEU Fission-Based Mo-99 Production with Low-Performance Research Reactors
}

\author{
S. Dittrich \\ GSG International GmbH, Eichenstr. 12, 8808 Pfaeffikon, Switzerland \\ Correspondence should be addressed to S. Dittrich; sven.dittrich@gsg-int.com
}

Received 18 August 2013; Accepted 4 November 2013

Academic Editor: George Vandegrift

Copyright (C) 2013 S. Dittrich. This is an open access article distributed under the Creative Commons Attribution License, which permits unrestricted use, distribution, and reproduction in any medium, provided the original work is properly cited.

Fifty years ago, one of the worldwide first industrial production processes to produce fission-Mo-99 for medical use had been started at ZfK Rossendorf (now: HZDR, Germany). On the occasion of this anniversary, it is worth to mention that this original process (called LITEMOL now) together with its target concept used at that time can still be applied. LITEMOL can be adapted very easily to various research reactors and applied at each site, which maybe still of interest for very small-scale producers. Besides this original process, two further and actually proven processes are suitable as well and recommended for small-scale LEU fission Mo-99 production also. They are known under the names KSA/KSS COMPACT and ROMOL LITE and will be described below.

\section{Introduction}

“The IAEA's Coordinated Research Project (CRP) on "developing techniques for small-scale indigenous production of Mo-99 from low enriched uranium or neutron activation" has been working since 2005 to assist participating countries to assess, evaluate, and implement nuclear technology for producing Mo-99 without highly enriched uranium in order to meet local nuclear medicine requirements" [1]. Within that CRP, a fact-finding mission performed by experts of IAEA cooperating with other independent experts could be applied for such providing substantial help in analyzing the given situation at a research center and the country/region around. This paper describes two process technologies and one specially developed target the latter was especially suitable and proven for the use of very low enriched uranium, both supporting this CRP and its philosophy and tools at the same time.

During the sixties of last century, fission Mo-99 began its significant upturn lasting up to today ("Fission-produced ${ }^{99} \mathrm{Mo}$ (f.p. ${ }^{99} \mathrm{Mo}$ ) of very high specific activity and alumina column based ${ }^{99 \mathrm{~m}} \mathrm{Tc}$ generators have remained the mainstay in the field as "gold standard"' ' [2]), mainly due to the new cold KITs and their need of very high specific Tc- $99 \mathrm{~m}$ solutions for labeling. About all research reactors, even those with thermal neutron flux densities down to $1 \times 10^{13} \mathrm{n} /\left(\mathrm{cm}^{2} \mathrm{~s}\right)$, are potential candidates for small-scale fission-based Mo-99 production covering the local or domestic demand of [ $\left.{ }^{99 \mathrm{~m}} \mathrm{Tc}\right]$ pertechnetate solutions of high specific activity for nuclear medicine diagnostic imaging procedures with homemade Tc-99 m generators. Adequate LEU targets are commercially available. An indigenous production of LEU targets as well as of very low enriched targets $\left(0.72 \%\left({ }^{\text {nat. }} \mathrm{U}\right)-5 \%{ }^{235} \mathrm{U}\right)$ is possible at local sites. Proven target manufacturing and Mo-99 processing technologies including waste management solutions fitting to the needs of small-scale producers are on the market, capable of establishing fission Mo-99 and Tc$99 \mathrm{~m}$ generator production cluster. Such clusters would allow countries and/or regions to develop indigenous production capacities to become independent from global Mo-99 market. This is especially helpful in cases of temporary world supply issues at which small generator producers and their customers suffer most. Furthermore, such initiatives will train indigenous specialists for broad applications at the national nuclear centers.

Although there are many attempts to classify research reactors [RRs], this paper will not look into those differences even if they may play a (smaller) role when irradiating uranium targets for radioisotope [RI] production. One aspect, however, is of some interest: the shape of RR-fuel, either clusters of (mostly) plates or single rods. 
In terms of RI production, RRs will mainly be evaluated not only by their power density which determines the n-flux density, but also by the operation hours per week and their space which can be made available for targets to be irradiated, either in-core or at the core border or even inside the reflector.

Besides institutions which manufacture their own targets, there are target manufacturers on the market who are able to deliver proven targets suitable for the different RR types. Most common are plate-type targets with dispersion meat and Aluminum cladding and proven pin-type targets with uranium metal pellets or dispersion meat, with both Aluminum or steel cladding, all in quite different shapes. If a new target design is needed, the target has to be tested by the operator and certified by the responsible authorities.

\section{Materials and Methods}

Actually, there is a wide range of different target concepts for fission Mo-99 productions, mainly originating from $\mathrm{HEU}$ to LEU conversions of the fission targets. Still common in routine business are proven aluminum or aluminum-alloy cladded, (LEU- or HEU-) uranium aluminide or uranium alloy dispersion targets as straight plates or cylindrical-or (rarely) pin-type targets (pin-type targets are used, e.g., in RBT6 and RBT10 research reactor at RIAR, Russian Federation [3]). However, many other target concepts have been developed and undergone testing, for example, target with meats made of uranium metal foils, uranium metal pellets, uranium silicide dispersion, uranium oxide dispersion, and high density uranium aluminide dispersion.

Besides the target designs, manufacturing, and applications, during the last 50 years different processes for fissionMo-99 production have been developed all over the world (in which each producer has its own process [4]), suited to dissolve one single or a group of similar targets, to remove all impurities out of the received Mo-99 solution, and to handle the wastes economically and safely. Alkaline and acidic solvents are in use, with or without additional oxidants and/or catalysts, in a single step or a two-step digestion. Using a two-step combination of alkaline solvent first and hydrofluoric acid with oxidant and catalyst afterwards, an ample scope of targets can be digested by one process [5], while alkaline nitrate solution has the ability to dissolute aluminum cladded, $\mathrm{UAl}_{x}$-aluminum dispersion targets without hydrogen generation [6].

The need to convert Mo-99 production facilities worldwide from processing HEU targets to used LEU targets [7-9] has led to clearly favoring targets with high U-density $[3,10-$ 15]. U-metal foils as targets are still struggling with encasing and handling issues [16]. The proven target with high Udensity on the market is already the $\mathrm{U}_{3} \mathrm{Si}_{2}-\mathrm{Al}$ target, which can rely on a proven process as well (see below).

On occasion to the named 50th anniversary of one of the first industrial process for fission Mo-99 production [17], it is worth to have a look onto that target it started with.

2.1. Very Low Enriched Target with Uranium Metal Pellets. A decision for a small-scale fission Mo-99 production is an evident attempt to become independent from global fission Mo-99 market when trying to meet local or regional Mo-99 needs by our own capacities. Apart from the global market which did not exist in the early sixties of the last century, all these arguments remain valid for developing countries.

In this context, supply with adequate and sufficient targets is playing an important role, and an indigenous target production, if possible, seems to be the method of choice. Also, a complete technology for a closed LEU cycle is available (for details see Section 2.3.1), consisting of a proven uranium recycling process and a proven target reproduction for aluminum cladded uranium silicide dispersion targets.

As an alternative to a closed LEU cycle (LEU meaning nearly $20 \%$ enriched ${ }^{235} \mathrm{U}$ ), the use of uranium metal pellets made of natural uranium or very low enriched uranium up to $5 \%{ }^{235} \mathrm{U}$ is described here for two reasons, besides that, those targets can be produced easily: first, those targets had been the fundament of one of the named first industrial production processes of small-scale fission Mo-99, and secondly this target concept generally is very interesting for small-scale fission Mo-99 still using low-performance RRs with neutron flux densities down to $1 \times 10^{13} \mathrm{n} /\left(\mathrm{cm}^{2} \mathrm{~s}\right)$. Moreover, those targets had permanently been used for around 15 years at $\mathrm{ZfK}$ Rossendorf (now: HZDR, Germany) [17].

Starting from metallic rods made of natural uranium (during the sixties imported from Russia, having diameters of $8.5 \mathrm{~mm}$ ), small pellets had been manufactured on a lathe, having a thickness of $4.2 \mathrm{~mm}$ each. The pellets were placed in an aluminum tube with spacers of aluminum between them and at both ends, in order to get the fission heat distributed more homogenously inside the rod. This spacing of pellets had helped avoiding hot spots and providing better heat conduction to the outer surface of the Aluminum rod. After welding and leakage test(s), the target was ready for irradiation (see Figure 1).

From experiences made, very low ${ }^{235} \mathrm{U}$ enrichment should be adapted to the available thermal neutron flux density at the irradiation position. Table 1 could provide a first and very rough orientation of such adaption which is solely based on experience with heat removal out of the pellets preventing baking together with the spacers.

After irradiation and the mandatory cooling-down period, the tube can be easily cut-off and the uranium metal pellets can be separated and dissolved using an actual smallscale process like the KSS COMPACT described further down. Very high uranium density and no aluminum dissolution mean less process waste and processing of higher amounts of uranium during a certain time interval, shorter than with aluminum dispersion targets. These are reasons why even with natural uranium in moderate thermal neutron flux densities remarkable activities of fission Mo-99 can be achieved.

However, it has to be emphasized that this target as well as its processing (see Section 2.2 ) is basic (but proven) technology for Mo-99 production at small scale. Therefore, it should not be compared with other processes described in this paper based on dispersion targets using LEU at $20 \%$ enrichment. 


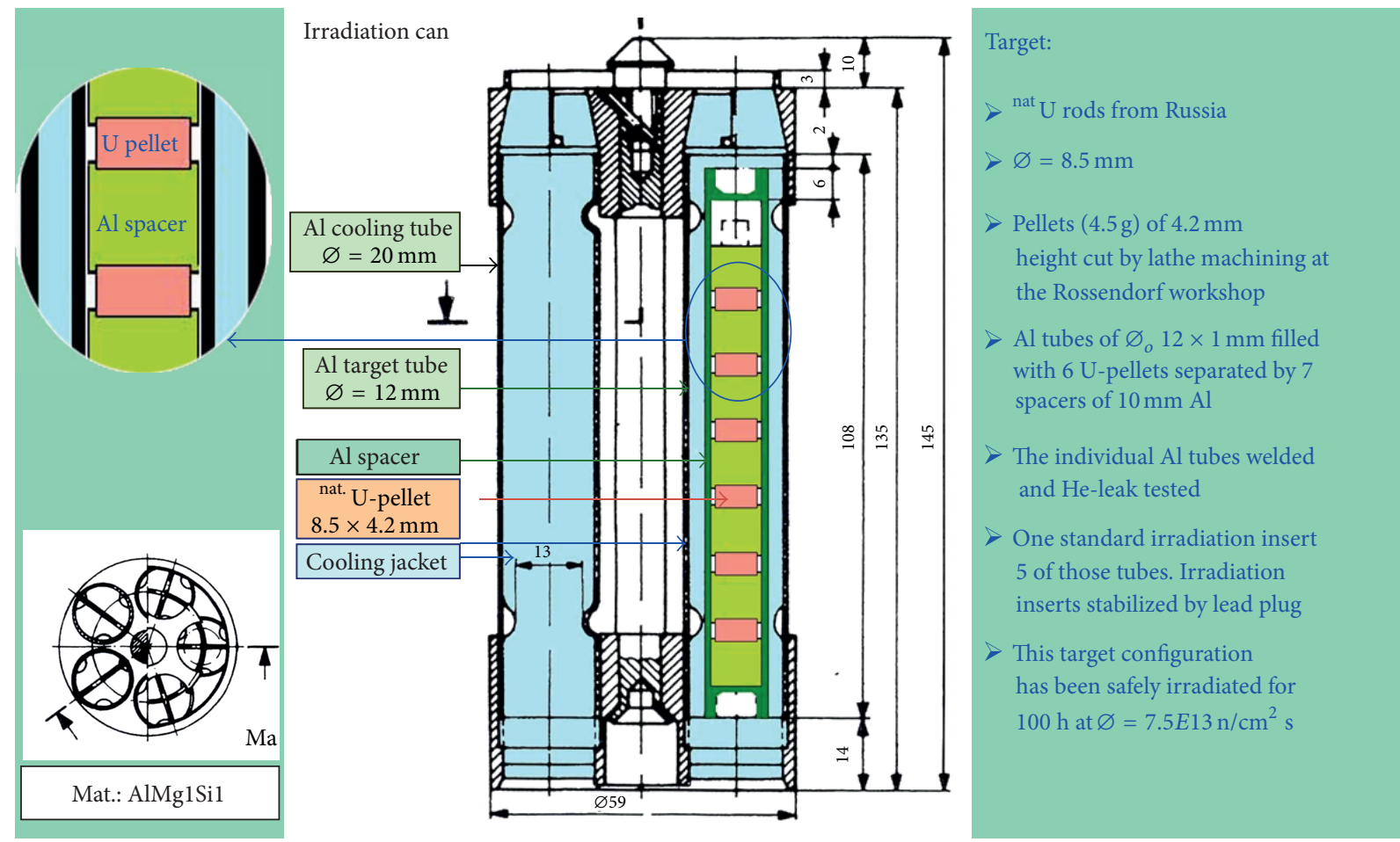

FIGURE 1: General design of an irradiation can with five very low enriched targets for fission Mo-99 production (taken from [18]).

TABLE 1: Flux density and corresponding U-enrichment for irradiation of very low enriched targets and given heat removal system capacity. Irradiating of $280 \mathrm{~g}$ of $\mathrm{U}$-metal pellets over $100 \mathrm{~h}$ with subsequent $20 \mathrm{~h}$ cooling time and about $10 \mathrm{~h}$ processing time, resulting in 550-740 GBq (15-20 Ci) Mo-99 (calibrated 6 days after end of production), is expected to be delivered under given effective thermal neutron flux densities with the suggested ${ }^{235} \mathrm{U}$ enrichments.

\begin{tabular}{lccccc}
\hline$n$ th-flux density $\left[n /\left(\mathrm{cm}^{2} \mathrm{~s}\right)\right]$ & $7 E 13$ & $5 E 13$ & $3 E 13$ & $2 E 13$ & $1 E 13$ \\
\hline$\left({ }^{235} \mathrm{U}\right)$ enrichment $[\%]$ & $0.7\left({ }^{\mathrm{nat}} \mathrm{U}\right)$ & 1.0 & 1.7 & 2.5 & 5.0 \\
\hline
\end{tabular}

\subsection{Historical Process: LITEMOL. One of the first industrial} processes for small-scale fission Mo-99 production had been originally developed for producing fission Te-132 to be used in Te-132/I-132 isotope generators. Under the economical restrictions during the cold war (during the early sixties of last century) and with limited availability of mainly "basic" chemicals, the process (now called LITEMOL) got the following design (see Figure 2).

This process with $\sim 70 \%$ yield (decay corrected) [19] in combination with the very low enriched targets described above had produced enough fission Mo-99 for a country like the former German Democratic Republic (GDR) with around 17 million inhabitants under the conditions and requirements of last century's sixties and seventies. For actual need, some adaptions are necessary, but it will be possible to get this process modernised with some supplementary R\&D.

2.3. Actual Processes: KSA/KSS COMPACT and ROMOL LITE. KSA/KSS COMPACT and ROMOL LITE are smallscale adaptations of large-scale KSA/KSS (KSA/KSS are two sides of the same coin, where KS stands for KARLSRUHESAMEH technology developed by Sameh [20-25] at the Karlsruhe Research Center (FZK, now: KIT), Germany. This technology has been successfully used already in full-scale productions processes for uranium Aluminide dispersion targets (KSA version: KARLSRUHE-SAMEH ALUMINIDE) and for uranium Silicide dispersion targets (KSS version: KARLSRUHE-SAMEH SILICIDE, see Figure 3), but practically, all other targets can be processed with KS technology, too.) and ROMOL-99 processes, widely proven for processing plate type dispersion targets. Such proves are performed at and by (a) ROMOL-99 at Pakistan Institute of Nuclear Science and Technology (PINSTECH, Islamabad), (b) KSA at Karlsruhe Institute of Technology (KIT, formerly Forschungszentrum Karlsruhe (FZK)), Germany, and at Mallinckrodt Medical, Netherlands, (c) KSS at KIT, and (d) pin-type dispersion targets of different shapes applying ROMOL-99 at State Scientific Center-Research Institute of Atomic Reactors (RIAR), Russian Federation.

Whatever target concept will be realized for a future small-scale fission Mo-99 production facility, KSA/KSS COMPACT, using a two-step combination of alkaline solvent first and hydrofluoric acid with oxidant and catalyst afterwards, is able to dissolve almost all of these targets (In uranium metal foil targets, zinc or aluminum (instead of nickel due to its well-known resistance against hydrofluoric acid) has to be electroplated on uranium metal foils as recoil barrier and for preventing bonding with the aluminum cladding.) digesting the uranium compound to diuranate fast and under reduced pressure to extract high specific fission Mo-99 in pharmaceutical grade with $\sim 90 \%$ yield 


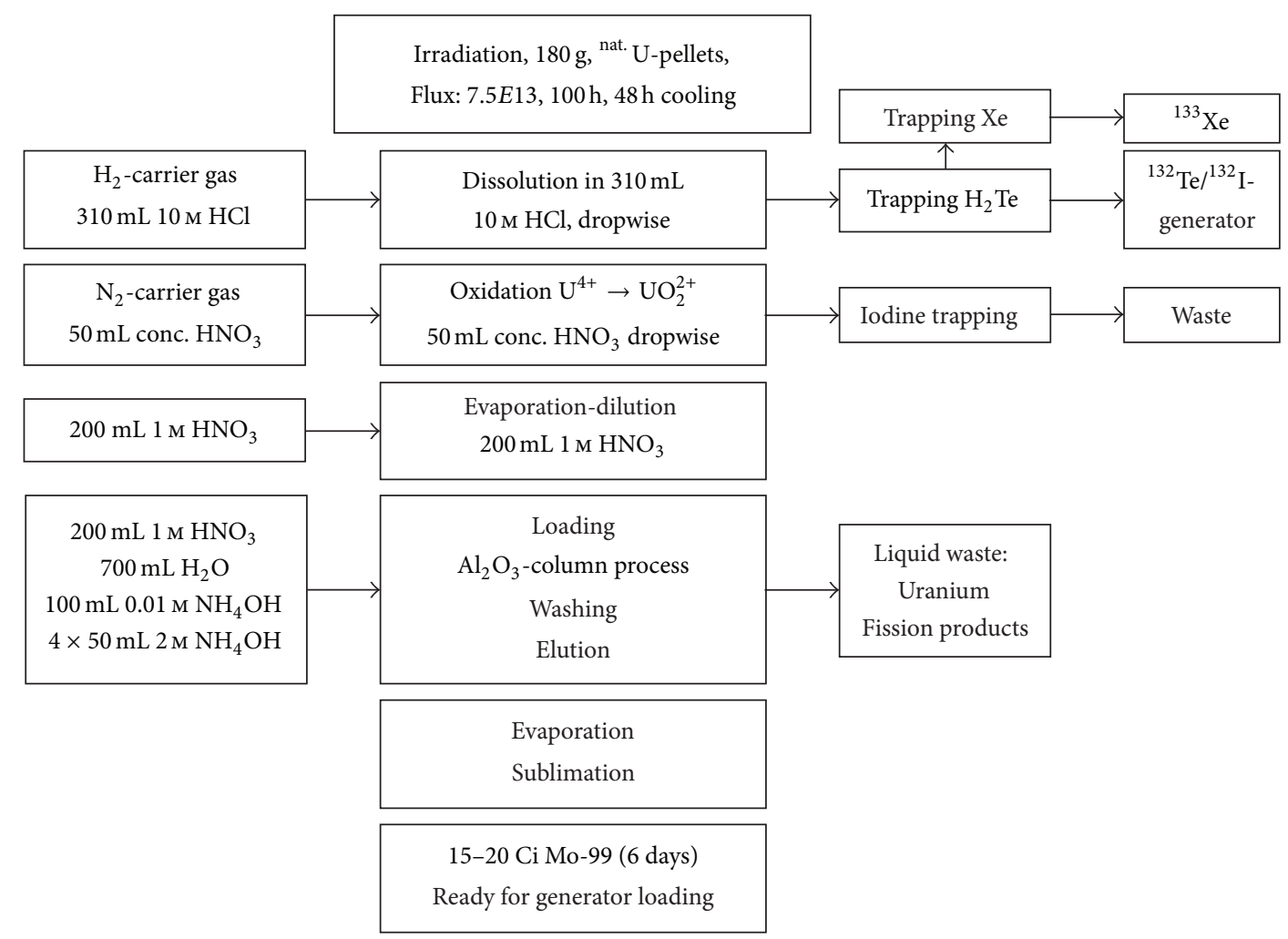

Figure 2: Process scheme (taken from [19]) describing one of the first industrial production processes for small-scale fission Mo-99 production (now called LITEMOL).

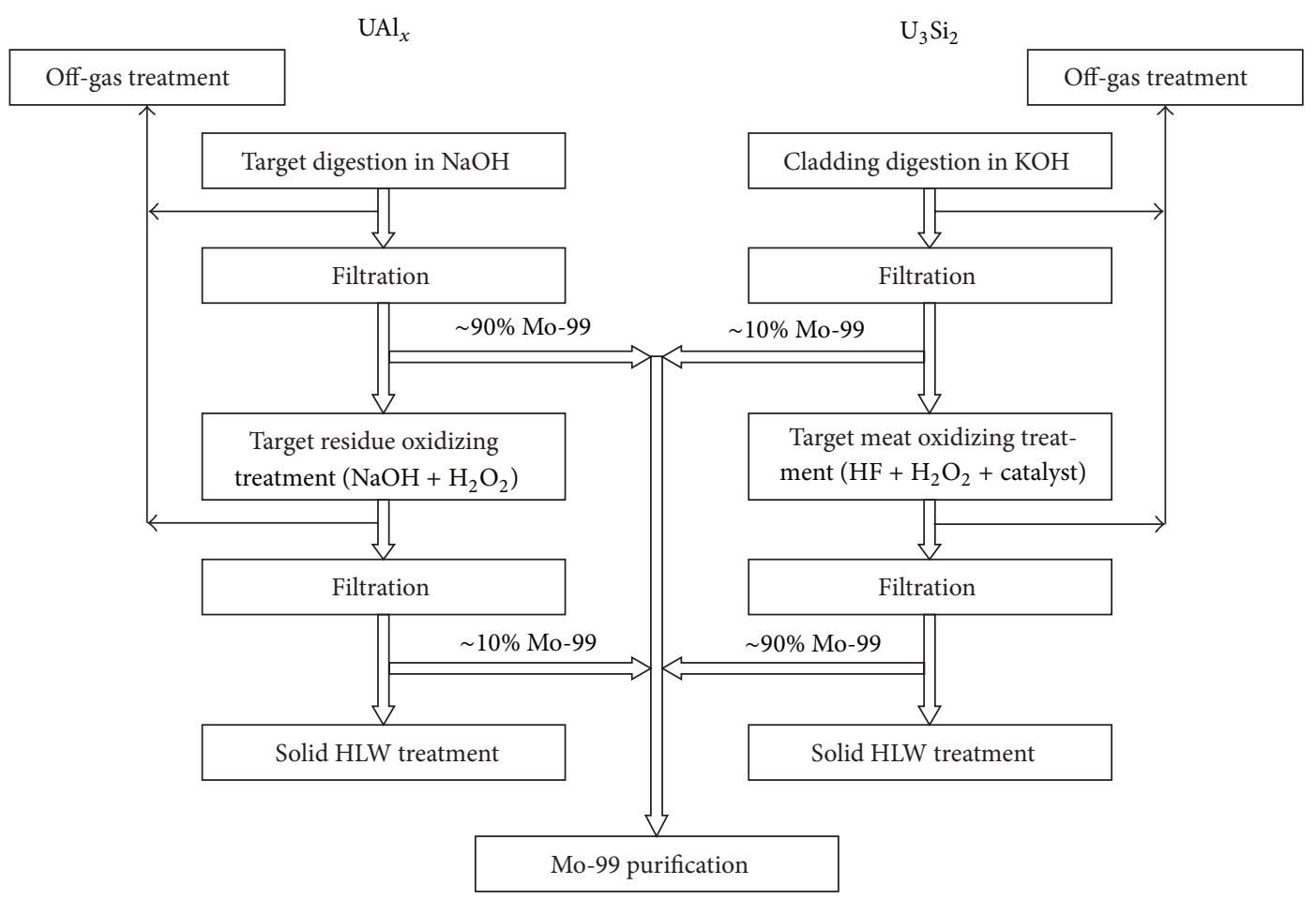

FIGURE 3: Flow scheme (in detail) of KSA/KSS production process showing the chemical treatment of $\mathrm{UAl}_{x}$ targets (left column) in comparison to other targets (right column, $\mathrm{U}_{3} \mathrm{Si}_{2}$ taken as example). 
(decay corrected) [5] in an overall $12 \mathrm{~h}$ process with very low environmental impact.

On the other hand, a technology avoiding any Hydrogen generation became more and more interesting for Mo-99 producers in the last decade. For that reason, ROMOL LITE process with overall $12 \mathrm{~h}$ processing time had been developed as downscaled adaption of ROMOL-99 process with $\sim 80 \%$ yield (decay corrected) [26] for dissolving LEU $\mathrm{UAl}_{x}$ dispersion targets under reduced pressure and-as said-without any Hydrogen generation, using an alkaline Nitrate solution which has been already routinely used in fission Mo-99 production at PINSTECH, Pakistan [27] as well as at two large-scale fission Mo-99 production lines at RIAR, Russian Federation [3].

2.3.1. KSA/KSS COMPACT [20-25]. (This section is based on methods and processes developed by and proven under responsibility of Sameh et al. at Karlsruhe Institute for Technology (KIT) for large-scale Mo-99 production. The version for aluminum cladded $\mathrm{UAl}_{x}$ dispersion targets (KSA) has been used since more than 15 years by Mallinckrodt Medical at Petten, The Netherlands, being second largest Mo99 producer worldwide. For small-scale processes, KSA/KSS has been modified and simplified to a downscaled version called KSA/KSS COMPACT by Sameh.)

KSA/KSS process in its compact version for small-scale LEU fission Mo-99 production starts after transportation of the targets into the HC-line consisting of minimum two hot cells with a two-step digestion under reduced pressure to get target cladding completely dissolved and meat digested.

In case of aluminum or aluminum alloy cladded, uranium aluminide or uranium alloy dispersion (LEU) targets of plateor pin-type, the proven KSA version could be the selected process. First step is a treatment in pure alkaline solution $(6 \mathrm{~m}$ $\mathrm{NaOH}$ ) dissolving the cladding plus digesting most of the meat of the target itself, followed by filtration. Around 90\% of the Mo-99 is found in the solution. In a second step, some residues from meat material are digested in alkaline solution of hydrogen peroxide. A precipitate is filtered off (filter cake) consisting of uranium (as diuranate) and the bulk of other impurities (e.g., actinides and group II, III, IV, V, and VI elements).

In case of any other target concept, especially when using the available $\mathrm{U}_{3} \mathrm{Si}_{2}-\mathrm{Al} \mathrm{LEU}$ targets with the so far highest $\mathrm{U}$ density of all proven plate-type targets, KSS version of that process is considered as favorable solution for gain-based facilities.

In the KSS version of the described process, the first dissolution step is a treatment in pure alkaline solution using Potassium Hydroxide (6 M KOH) instead of sodium Hydroxide followed by filtration. Some Mo-99 will be found in the solution, but most of it remains in the nondissolved residue of the meat, which is treated in a second step with $5 \mathrm{M}$ hydrofluoric acid supplemented by $7.5 \%$ hydrogen peroxide and halogen catalyst $\left(0.02 \mathrm{M} \mathrm{KIO}_{4}\right)$.

Under reduced pressure, a smooth carrier gas stream (e.g., helium) takes all gaseous fission products and generated hydrogen out of the dissolvers passing a Copper-(II) oxide

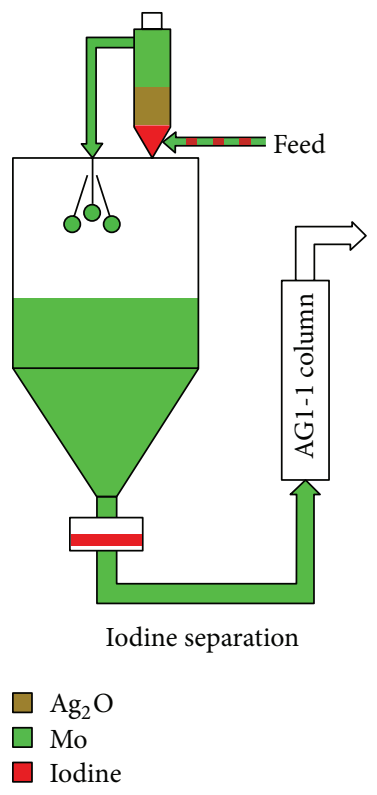

FIGURE 4: Separation of Iodine (taken from [23]) using a floating bed of hydrated Silver oxide and a filter, KSA/KSS process.

oven (for complete oxidization of hydrogen to water) with condenser (for drying the gaseous stream) into a vacuum tank for intermediate storage. After End of Production, the vacuum tank is evacuated for the next production and the gaseous fission products (mainly Xenon-isotopes) are retained on a battery of Charcoal columns cooled to $15^{\circ} \mathrm{C}$, for decay. Alternatively, the radioxenon could be separated from the gaseous mixture for further use.

The acidic solution from the second digestion step of other than $\mathrm{UAl}_{x}$ aluminum dispersion targets will be alkalized to $2-3 \mathrm{M} \mathrm{KOH}$ and some hydrogen peroxide is added before merging the two solutions from both digestion steps. Thus, after destroying some excess of hydrogen peroxide by boiling, alkaline solutions with some hydrogen peroxide added after filtration is the vantage for Mo-99 purification.

The subsequent Mo-99 purification is the same with KSA and KSS version of that process, independently from the targets mentioned. This is the main reason for putting both variants together as KSA/KSS process. The purification is started with Iodine separation on a floating bed of hydrated silver oxide, followed by four chromatographic steps and ending up in a high temperature treatment in Platinum crucibles. Solid waste (mainly filter cake and tubes) is locked out, taking the same way back which the targets came. Liquid waste is pumped into tanks below the hot cells for intermediate storage.

Alkaline filtrate of digested targets feeds a floating bed of hydrated silver oxide. The silver oxide is reduced by hydrogen peroxide to fine particles of silver metal and Iodine is strongly adsorbed on the silver surface. Bigger particle stays in the floating bed, smaller ones will be filtered off (see scheme of Figure 4 ). The silver metal/silver iodide mixture is ready for an easy fission-Iodine-131 production taking place in a separate hot cell or will be stored for decay, while 


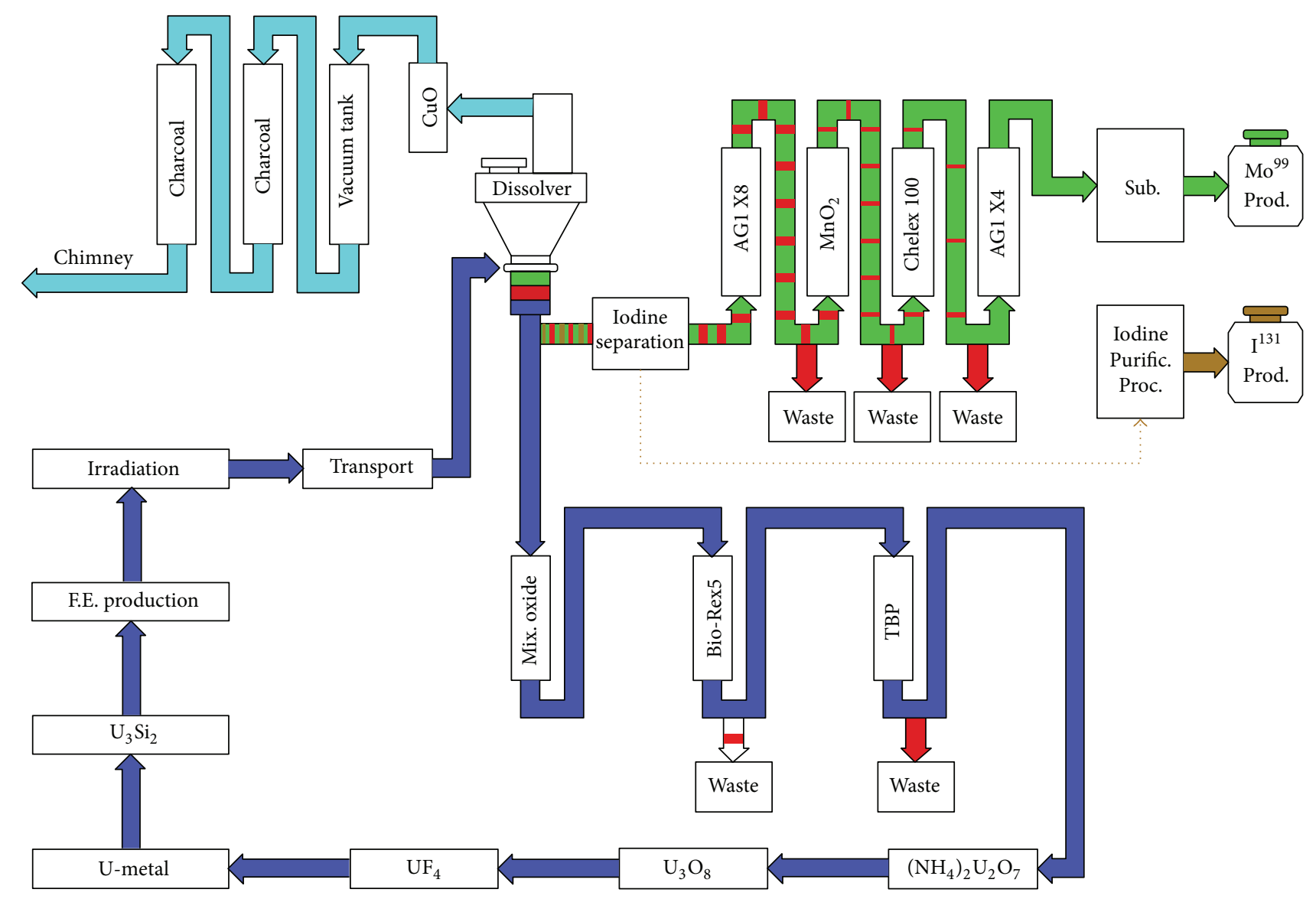

FIGURE 5: Process scheme of complete and closed KSS process variant (taken from [23]), completely proven with $\mathrm{U}_{3} \mathrm{Si}_{2}-\mathrm{Al}_{\text {dispersion targets. }}$

the filtrate feeds the first chromatographic column (AG1-X8, $\mathrm{OH}^{-}$-form, 200-400 mesh, Bio-Rad, USA), where Mo-99 is quantitatively retained as Molybdate. The feed solution is collected in an intermediate storage tank as liquid high-level waste (HLW).

AG1-X8 column is washed with $3 \mathrm{M} \mathrm{KOH}$ and molybdenum elution is carrying on using a $2 \mathrm{M}$ sodium nitrate solution containing $1 \mathrm{M}$ Nitric acid. This solution feeds the manganese dioxide column (hydrated manganese oxide, $\mathrm{MnO}_{2} \times n \mathrm{H}_{2} \mathrm{O}$, particle size of 0.2 to $0.5 \mathrm{~mm}$ (finer particles being removed by aqueous sedimentation)). In that column Mo-99 is quantitatively retained together with accompanying fission products, while all anionic species and the alkaline cations are removed with the feed solution and sucked into a slightly-evaporated intermediate storage tank for liquid low and intermediate level waste.

After washing the column with $1 \mathrm{M}$ nitric acid and distillated water, the whole manganese oxide bed together with the molybdenum adsorbed is dissolved by a solution of $2 \mathrm{M}$ Sulfuric acid supplemented by $0.2 \mathrm{M}$ ammonia thiocyanate, $0.05 \mathrm{M}$ sodium sulphite, and $0.001 \mathrm{M}$ potassium iodide.

A Chelex 100 column is fed with that manganese oxide solution. Chelex 100 is a styrene divinylbenzene copolymer with iminodiacetate functional groups. Depending on the conditions, Chelex 100 can be used as weak cationic as well as weak anionic exchanger. From the acidic solution, molybdenum is retained quantitatively as negatively charged molybdenum hexathiocyanato complex $\left[\mathrm{Mo}(\mathrm{SCN})_{6}\right]^{3-}$, while manganese ions and fission product species are not adsorbed. The column is washed by Sulfuric acid supplemented by $0.2 \mathrm{M}$ ammonia thiocyanate, pure Sulfuric acid, and water.

Molybdenum is easily desorbed from Chelex 100 under oxidizing alkaline conditions as Molybdate-(VI), with Chelex 100 meanwhile acting as a weak cationic exchanger. The desorption is carried out with sodium hydroxide solution containing some hydrogen peroxide which is becoming the feed solution for the last chromatographic column filled with AG1-X4 ( $\mathrm{OH}^{-}$-form, 200-400 mesh, Bio-Rad, USA). This column is used for the desalination of the Mo-solution by washing with water before eluting the Mo-99 with Nitric acid to avoid the formation of mixed oxides with molybdenum.

The nitric acid solution of molybdenum is evaporated to dryness and subsequently the Mo(VI)-oxide sublimated at $1000^{\circ} \mathrm{C}$ in Platinum crucibles and condensed in a quartz condenser. This high temperature treatment ensures complete destruction of all organic impurities introduced during the process and eliminates possibly introduced corrosion products such as Iron, nickel, cobalt, or chromium by burning them to the so-called highly burned oxides. Mo(VI)-oxide 


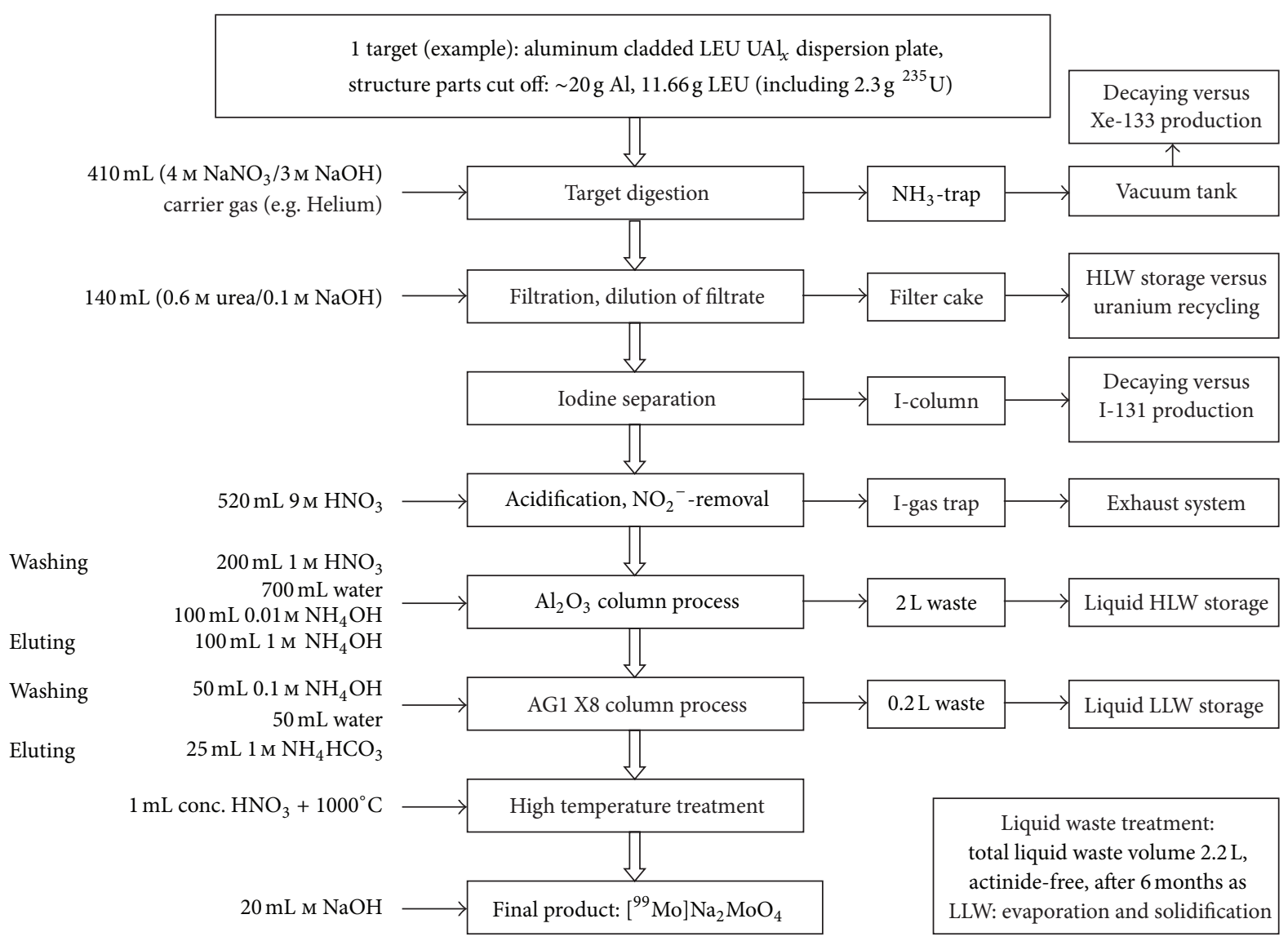

FIGURE 6: Process scheme for ROMOL LITE, example using one commercially available target plate. The processing of several plates is of course possible.

is dissolved in ammonia and finally adjusted with sodium hydroxide, while the ammonia is evaporated as very last step.

Due to the very low burn-up in LEU targets for smallscale fission Mo-99 productions, own target production based on a complete uranium recycling process might/should be considered. Figure 5 depicts the scheme of a closed process completely proven for $\mathrm{U}_{3} \mathrm{Si}_{2}-\mathrm{Al}$ dispersion targets being operated at KIT, Germany.

The off-gas treatment (described above), within KSA/KSS process which is used with the KSA version of the process by Mallinckrodt Medical at Petten under a KIT license for more than 15 years, is a unique technique leading to more than three orders of magnitude lower radioxenon release in comparison to other large-scale fission Mo-99 producers [28].

The idea of a worldwide voluntary limitation of radioxenon release to $5 \mathrm{GBq} /$ day generated at WOSMIP $[29,30]$ for all Mo-99 producers is a reality for the operation at Petten site since 15 years-an advantage which certainly is as well available with the compact version foreseen for small-scale LEU fission Mo-99 producers.

2.3.2. ROMOL LITE. ROMOL LITE is the downscaled ROMOL-99 process; the latter developed and was proven for large-scale fission Mo-99 production comprising the special feature of dissolving $\mathrm{UAl}_{x}-\mathrm{Al}$ dispersion targets without hydrogen generation, but being limited to distinctly lower dense $\mathrm{UAl}_{x}$-Al LEU targets than the a.m. KSS COMPACT process (see Figure 6).

Using alkaline solution ( $3 \mathrm{M}$ sodium hydroxide) of $4 \mathrm{M}$ sodium nitrate, the target(s) will be completely digested under reduced pressure at $(70 \pm 10)^{\circ} \mathrm{C}$. A smooth carrier gas stream (e.g., Helium) takes all gaseous fission products and generated ammonia out of the dissolver through an ammonia trap (filled with $5 \mathrm{M}$ Sulfuric acid) and a condenser (to dry the gaseous stream) into a vacuum tank for intermediate storage. After end of production, the vacuum tank is evacuated again for the next production and gaseous fission products (mainly Xenon isotopes) are retained for decay on a battery of flasks filled with suitable zeolite.

A precipitate consisting of uranium (as di-uranate) and a bulk of other fission impurities (e.g., actinides and group II, III, IV, V, and VI elements) is filtered off. After decay of short lived isotopes ( 6 months after end of production) in a separate intermediate solid HLW storage at site, 99.4\% activity of all wastes is accumulated in the filter cake, canned for long-term solid HLW storage (or used for re-cycling) in tight stainless steel boxes, while only $0.6 \%$ of the activity remains in the liquid ILW or LLW for further waste management [18].

Subsequently, the Mo-containing filtrate passes through a column filled with silver-coated acidic alumina [31] for 
separation of Iodine isotopes and is acidified to $0.4 \mathrm{M}$ Nitric acid afterwards. After adding on some urea, the solution is boiled under reflux to convert any nitrite into nitrogen.

Cooled down to ambient temperature, that acidic solution feeds an alumina column (aluminum oxide 90 active acidic (0.063-0.200 mm), Merck, Germany), where Mo-99 is absorbed as molybdate-VI. Washed first with $1 \mathrm{M}$ nitric acid, water and $0.01 \mathrm{M}$ ammonia, Mo-99 is eluted with $1 \mathrm{M}$ ammonia.

That ammoniac eluate feeds the AG1 X8 column (AG1$\mathrm{X} 8, \mathrm{OH}^{-}$-form, 200-400 mesh, Bio-Rad, USA) adsorbing molybdate-VI. After washing with water, molybdenum is desorbed by $1 \mathrm{M}$ ammonium bicarbonate.

After adding some $1 \mathrm{~m}$ nitric acid, the solution is boiled and evaporated for destroying any organic impurities. Typically and at that stage already, the final product meets all requirements and is therefore solved in the solvent of choice, usually diluted sodium hydroxide. For getting rid of any impurities potentially having remained in the product, an optional high temperature treatment could be applied.

\section{Results and Discussion}

A widely variable adaption of both of the processes, KSA/KSS COMPACT and ROMOL LITE, to local conditions and requirements is possible despite their original design/development for large-scale production predominantly. Both being proven, first efforts have been made to scale them down during the last years. Thus, their scope of application now covers all sizes of production, from very small scale to very large scale. As an option, production supplemented by a complete uranium cycle (uranium recycling and target production on site) is well proven available, too.

A long-term proven target for natural or very low enriched uranium has been described. The use of uranium metal pellets and the possibility to separate the uranium from the aluminum spacers and the aluminum canning after irradiation allow small-scale production of remarkable activities of fission Mo-99 in RRs with thermal neutron flux densities down to about $1 \times 10^{13} \mathrm{n} /\left(\mathrm{cm}^{2} \cdot \mathrm{s}\right)$.

These technologies should enable operators of RRs of moderate performance to envisage production of indigenous fission Mo-99 for their countries/regions, in order to become independent from global market and to give their engineers and scientists an additional long-term perspective in their countries.

\section{Conclusions}

50 years ago, one of the worldwide first industrial production processes able to produce fission Mo-99 for medical use had come to life at ZfK Rossendorf (now: HZDR, Germany). It is around the occasion of this anniversary that original process (called LITEMOL now) together with its target concept used that time has been revived. The original target concept can be easily adapted to the conditions and needs of different research reactors and easily produced at their sites. Both process and target still may be of interest for very small-scale producers of Mo-99, provided that some slight adaptions to the actual requirements have been performed. In order to deliver a complete picture of the possibilities of small-scale production in our days, the two proven and actually applied processes downsized for the so-called small-scale LEU fission Mo-99 production have been described in detail as well: KSA/KSS COMPACT and ROMOL LITE.

\section{Acknowledgments}

For the description of the various processes and historical facts, the author relied on oral information and support of one of the first Mo-99 production pioneers worldwide, Gerhard Wagner at that time, in 1963, researcher and later on Head of Isotope Production at ZfK Rossendorf (now: HZDR), Germany, for decades, is still working as Senior Advisor to GSG International GmbH, and also Dieter Novotny, the "father" of this uranium metal pellets target concept, at that time Technician at ZfK Rossendorf (now: HZDR), Germany, later on for decades as Head of the Rossendorf workshop and became later on the Managing Director of the Rossendorf branch of HWM (Wälischmiller), is still among the experienced Senior Managers at GSG International GmbH. For the preparation of this paper, the author was substantially supported by H.-J. Roegler, Consultant for about all matters of research reactors and their utilization.

\section{References}

[1] I. N. Goldman, N. Ramamoorthy, and P. Adelfang, "Fostering new sources of Mo-99 for international nuclear medicine needs: the contribution of the IAEA coordinated research project on Molybdenum-99 production from LEU or neutron activation," in Proceedings of the RETR International Meeting on Reduced Enrichment for Research and Test Reactors, Washington, DC, USA, October 2008.

[2] N. Ramamoorthy, "Production and supplies of ${ }^{99} \mathrm{Mo}$ : lessons learnt and new options within research reactors and neutron sources community," in Proceedings of the IAEA International Conference on Research Reactors, Rabat, Morocco, November 2011.

[3] R. Kuznetsov and A. Svyatkin, "Mo-99 production at JSC "SSC RIAR": status, LEU conversion plan," in Proceedings of the IAEA 1stCoordination Meeting on INT1056: Supporting Small Scale, Non-Highly Enriched Uranium (Non-HEU) Molybdenum-99 Production Capacity for Nuclear Medicine Applications, Vienna, Austria, February 2013.

[4] G. F. Vandegrift, C. Conner, J. Sedlet et al., "Progress in chemical processing of LEU targets for ${ }^{99}$ Mo production 1997," in Proceedings of the International RERTR Meeting, Jackson Hole, Wyo, USA, October 1997.

[5] A. A. Sameh, Private Communication, 2013.

[6] S. Dittrich, "Turn-key customized non-HEU fission Mo-99 production facilities (Small Scale)," in Proceedings of the IAEA 1st Coordination Meeting INT1056: Supporting Small Scale, Non-Highly Enriched Uranium (Non-HEU) Molybdenum-99 Production Capacity for Nuclear Medicine Applications, Vienna, Austria, February 2013.

[7] P. Staples, "GTRI Mo-99 Program," in Proceedings of the IAEA 1st Coordination Meeting INT1056: Supporting Small Scale, 
Non-Highly Enriched Uranium (Non-HEU) Molybdenum-99 Production Capacity for Nuclear Medicine Applications, Vienna, Austria, February 2013.

[8] M. A. Pomper, "Time for an international commitment to end use of HEU for Mo-99," in Proceedings of the Mo-99 Topical Meeting, Chicago, Ill, USA, April 2013.

[9] M. Ahmad, "Molybdenum-99/technetium-99m management: race against time," Annals of Nuclear Medicine, vol. 25, no. 9, pp. 677-679, 2011.

[10] G. Ball, "Status update on the ${ }^{99}$ Mo HEU/LEU conversion project in South Africa," in Proceedings of the Mo-99 Topical Meeting, Chicago, Ill, USA, April 2013.

[11] R. W. Brown, "Update on Mallinckrodt's low-enriched uranium (LEU) conversion project," in Proceedings of the Mo-99 Topical Meeting, Chicago, Ill, USA, April 2013.

[12] H. J. Ryu, M. S. Sim, J. M. Nam, S. J. Jang, C. K. Kim, and J. M. Park, "Characterization of dispersion Mo-99 targets using atomized powder," in Transactions from European Research Reactor Conference, pp. 69-74, Saint Petersburg, Russia, 2013.

[13] M. Ciocanescu and G. F. Vandegrift, "High density LEU annular target qualification," in Proceedings of the Mo-99 Topical Meeting, Chicago, Ill, USA, April 2013.

[14] V. Host, "Progresses on IRE's LEU conversion program," in Proceedings of the Mo-99 Topical Meeting, Chicago, Ill, USA, April 2013.

[15] G. F. Vandegrift, C. Conner, S. Aase et al., "RERTR progress in Mo-99 production from LEU," in Proceedings of the 6th International Topical Meeting Research Reactor Fuel Management (RRFM '02), Gent, Belgium, March 2002.

[16] J. Creasy, "Update on the development, testing, and manufacture of high density LEU-foil targets and processing for the production of Mo-99," in Proceedings of the Mo-99 Topical Meeting, Chicago, Ill, USA, April 2013.

[17] O. Hladik, K. Jantsch, and G. Wagner, "Entwicklung der spaltproduktproduktion im ZfK rossendorf," Isotopenpraxis, vol. 19, no. 12, pp. 409-411, 1983.

[18] G.-J. Beyer, "German experiences in fission-based Mo-99 and recent revitalization by GSG," in Proceedings of the Technical Meeting on Developing Techniques for Small Scale Indigenous Molybdenum-99 (Mo-99) Production Using Low Enriched Uranium (LEU) Fission or Neutron Activation, Santiago, Chile, November 2010.

[19] D. Novotny and G. Wagner, "Procedure of small scale production of Mo-99 on the basis of irradiated natural uranium metal as target," in Proceedings of the Consultants Meeting on "Small Scale Production of fission Mo-99 for Use in Tc-99m Generators", IAEA, Vienna, Austria, July 2003.

[20] W. Leifeld and A. A. Sameh, "Method for separation of molybdenum, USA 5.508.010," Patent DE4231955 (1994), 1996.

[21] A. A. Sameh, "Production of fission Mo-99 from LEU uranium silicide target materials," in Invited Papers on Symposium on Isotope and Radiation Applications, pp. 111-135, R.O.C, LungTan, Taiwan, May 2000.

[22] A. A. Sameh, "Advances in Minimization of Fission Gas Release and Nuclear waste from Large Scale Fission Mo-99 Production Facilities," in Proceedings of the Workshop on Signatures of Medical and Industrial Isotope Production (WOSMIP '09), Strassoldo, Italy, July 2009.

[23] A. A. Sameh, "Minimization of fission nuclide release from large-scale Mo-99 production facilities by combining processing and off gas handling technology," in Proceedings of the Workshop on Signatures of Medical and Industrial Isotope Production II (WOSMIP II '11), Strassoldo, Italy, June 2011.

[24] Z. I. Kolar, W. J. C. Okx, and J. L. Kloosterman, "Assessment of molybdenum-99 production from high-enriched uranium (HEU) targets in comparison with that from low-enriched uranium (LEU) targets," Report, Delft University of Technology, Interfaculty Reactor Institute, Delft, Netherlands, 2002.

[25] A. A. Sameh and H. J. Ache, "Production techniques of fission molybdenum-99," Radiochimica Acta, vol. 41, pp. 65-72, 1987.

[26] R. Kuznetsov, Private Communication, RIAR, Dimitrovgrad, Russia, 2013.

[27] M. Ahmad, "Production of molybdenum-99 at PINSTECH, Islamabad," in Proceedings of the IAEA Technical Meeting on Developing techniques for small scale indigenous Molybdenum99 (Mo-99) production using low enriched uranium (LEU) fission or neutron activation: Specific waste and quality issues, Santiago, Chile, November 2010.

[28] M. Matthews, P. Saey, T. Bowyer et al., "Workshop on signatures of medical and industrial isotope production-a review," PNNL 19294, 2010.

[29] I. M. Cameron, "Engagement between the medical isotope production and the nuclear explosion monitoring communities," in Proceedings of the Mo-99 Topical Meeting, Chicago, Ill, USA, April 2013.

[30] T. W. Bowyer, R. F. Kephart, P. W. Eslinger, J. I. Friese, H. S. Miley, and P. R. Saey, "Maximum reasonable radioxenon releases from medical isotope production facilities and their effect on monitoring nuclear explosions," Journal of Environmental Radioactivity, vol. 115, pp. 192-200, 2013.

[31] M. V. Wilkinson, A. V. Mondino, and A. C. Manzini, "Separation of iodine produced from fission using silver-coated alumina," Journal of Radioanalytical and Nuclear Chemistry, vol. 256, no. 3, pp. 413-415, 2003. 


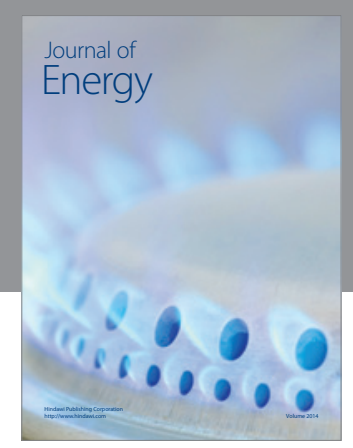

Journal of

Industrial Engineering
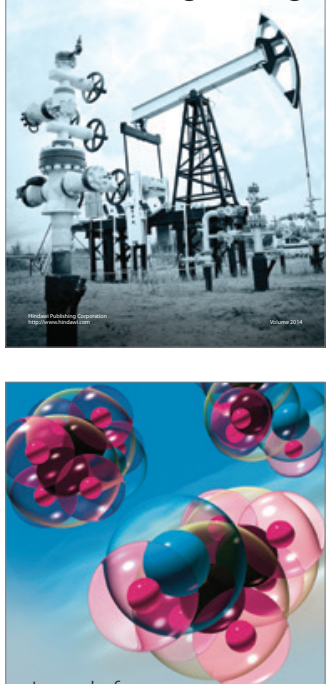

Fuels
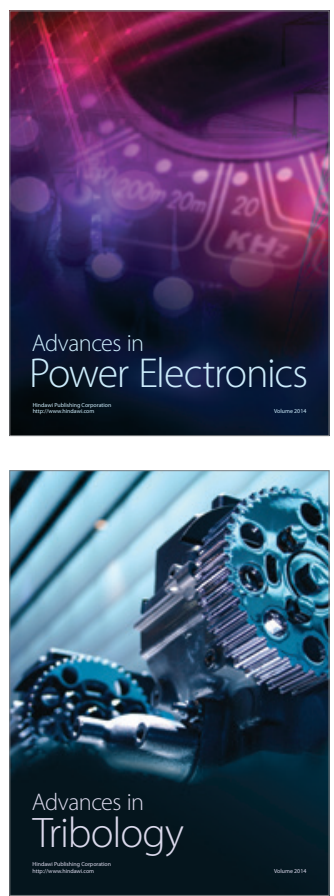

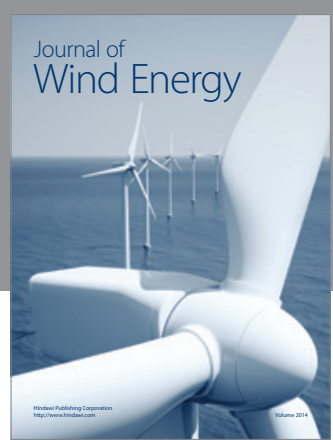

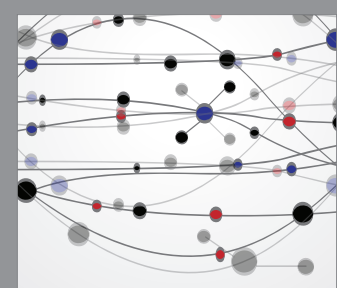

The Scientific World Journal

Submit your manuscripts at http://www.hindawi.com

Journal of

Structures
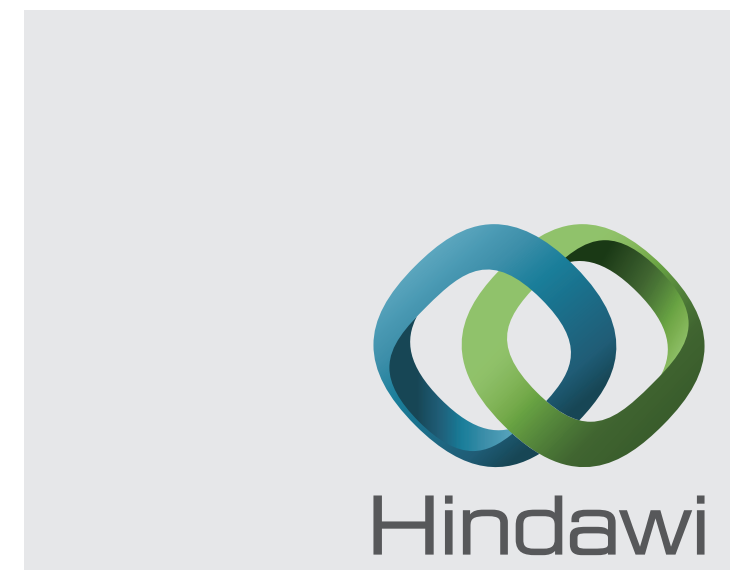

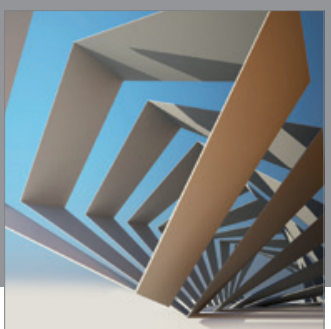

Rotating

Machinery
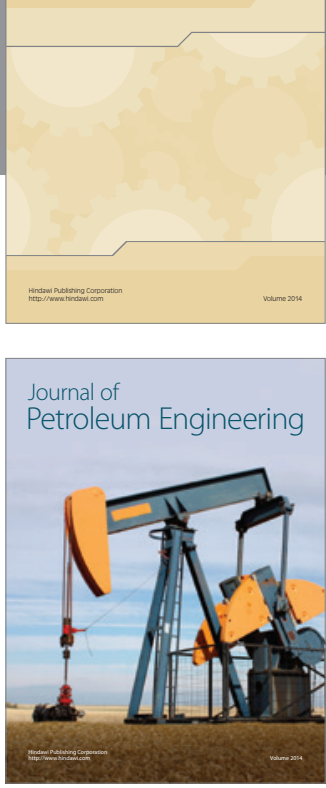

Journal of

Solar Energy
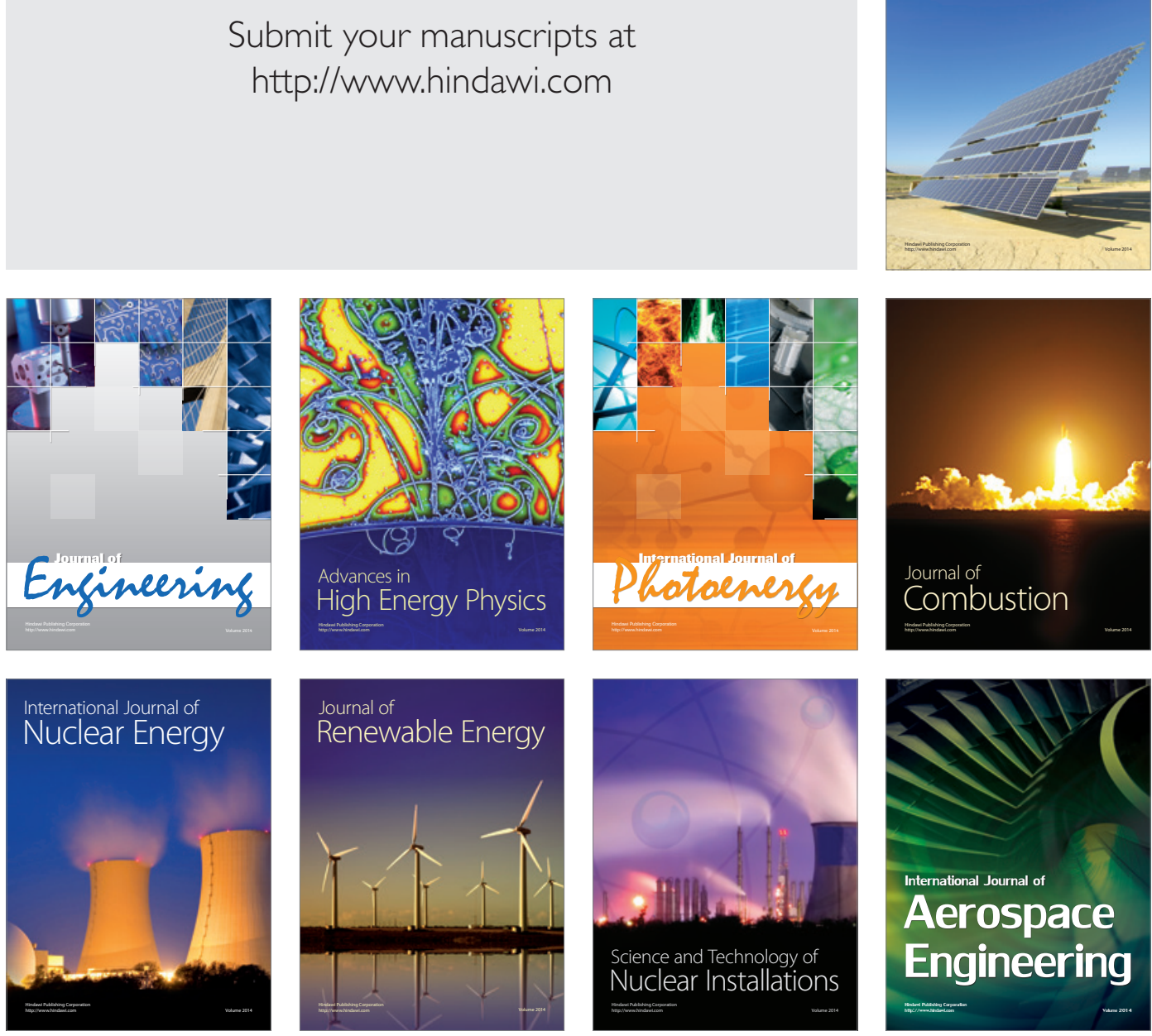